\title{
Physician, heal thyself: Creative writing as a tool for self-care and enhancing care of others
}

\author{
I was afraid that ... conforming to the modes of behaviour expected \\ of a doctor would distort my sense of self and my passion for art. \\ - AS (second-year medical student)
}

To the Editor: In his recent article in the SAMJ, ${ }^{[1]}$ Prof. Steve Reid questions whether inclusion of art and humanities in the medical curriculum can improve the flexibility and skill of a graduate.

As a writer and a general practitioner, I have struggled with the split between my artistic life and that of working with the ill, the injured and the emotionally hurt. As a student, I developed a chronic condition; although medication helped limit morbidity, it was my practise of taking emotional difficulty to the page that helped me manage stressors that adversely impacted on my health.

Wishing to pass on tools that helped me look after myself, I run workshops in memoir writing, and wrote a book titled Eloquent Body. ${ }^{[2]}$ Recently, I was invited to mentor four medical students in a writing project.

Since 2011, Prof. Reid has offered groups of second-year University of Cape Town medical students the option to research the relationship between art and medicine during a one-month special studies module (SSM). An accomplished musician, Prof. Reid knows the life-enhancing benefits of artistic practice, and was concerned that medicine excluded this valuable component of health.

The four components of the 'writing and health' SSM were: selfexploration through writing; noticing how language and the patient's narrative are controlled in medical settings; a literature search on creative writing and its effects on health; and a visit to hospitalised patients, comparing strengths and weaknesses of medical historytaking with an open-ended conversation where patients used their own language to frame their experience.

Scientists use objective measurement to determine what constitutes illness, and which interventions are effective. Most artists work intuitively from a subjective space, distilling the essence of experience that reflects on the human condition.

The students wrote:

AS: 'I thought I would be told what to do, as in the rest of medical studies. I didn't realise that I would have to find my own way, 
following my interests, and that it would be about me. Finding out about myself is going to make me a better doctor.'

PN: 'Since becoming a medical student, I don't have time to write, and it is starting to make me feel ill.... We are taught to put our own thoughts and emotions aside as if there is no place for them. As a result I lost sight of the human aspect within medicine.'

Is there evidence supporting art as a serious component in medical education? Many disciplines jostle for more time on the academic calendar.

To deliver appropriate care, we need to develop skills such as empathy that are difficult to teach. My medical education was filled with incidents where patients received quality treatment but were badly treated.

$\mathrm{ZW}$ : 'Reflective writing requires retreating into the subconscious, allowing for self-awareness, ${ }^{[3]}$ thus facilitating the inspection of beliefs and values, internal conflicts and dealing with strong emotions. ${ }^{[4]} \ldots$ Writing slows down the whirlwind of medical education and allows students to make sense of their experience on their own terms.'

Writing a memoir is a form of debriefing and reflection. Taking circumstances that are troubling, whether an interaction with an infuriating colleague or patient, a personal loss or an illness, and giving the feelings a shape through words or other art forms has many tangential and unexpected benefits for both self-care and relationships.

I recommend The Artist's Way ${ }^{[5]}$ to depressed patients; a colleague sends her stressed patients off to art or dance classes. Art is a way back to ourselves, a way of paying attention to what is going on below the radar of the mind, and a way of managing anxiety and stress.

PN: '[Creative writing] may not be part of my assessments, but it increases the quality of my life. It helps me to cope with my experiences in order to prevent the cynicism and disillusionment found to plague medical students. ${ }^{\text {?[6] }}$

\section{Dawn Garisch}

Author, workshop facilitator and part-time general practitioner dawn.garisch@gmail.com

1. Reid S. The 'medical humanities' in health science education in South Africa. S Afr Med J 2014;104(2):109-110. [http://dx.doi.org/10.7196/SAMJ.7928]

2. Garisch D. Eloquent Body. Cape Town: Modjaji Books, 2012

3. Shapiro J, Shafer A, Kasman D. Words and Wards: A model of reflective writing and development of reflective capacity in medical education. J Gen Intern Med 2010;25(7):746-749. [http://dx.doi. org/10.1007/s11606-010-1347-4]

4. Hatem D, Ferrara E. Becoming a doctor: Fostering humane caregivers through creative writing. Patient Educ Couns 2001;45(1):13-22. [http://dx.doi.org/10.1016/S0738-3991(01)00135-5]

5. Cameron J. The Artist's Way: A Course in Discovering and Recovering Your Creative Self. London: Pan Macmillan, 1995.

6. Shapiro J, Rucker L. Can poetry make better doctors? Teaching humanities and arts to medical students and residents at the University of California. Acad Med 2003;78(10):953-957. [http://dx.doi. org/10.1097/00001888-200310000-00002]

S Afr Med J 2014;104(4):257-258. DOI:10.7196/SAMJ.8063 